\title{
The Sharp Edge Flight Experiment SHEFEX II, a Mission Overview and Status
}

\author{
H.Weihs, J.Longo, J.Turner \\ German Aerospace Center, DLR
}

\begin{abstract}
After the successful flight of SHEFEX I the next mission is under development. Within this paper the basic goals and architecture of the SHEFEX II mission will be presented. Also launched by a two staged sounding rocket system SHEFEX II will be a consequent next step in technology test and demonstration. Considering all experience and collected flight data obtained during the SHEFEX I Mission, the test vehicle will be re-designed and extended by an active control system, which allows active aerodynamic control during the re-entry phase. Thus, ceramic based aerodynamic control elements like rudders or flaps, mechanical actuators and an automatic electronic control unit will be implemented. Special focus will be taken on improved GNC Elements. In addition, some other experiments including an actively cooled thermal protection element, advanced sensor equipment, high temperature antenna inserts etc. are part of the SHEFEX II experimental payload.
\end{abstract}

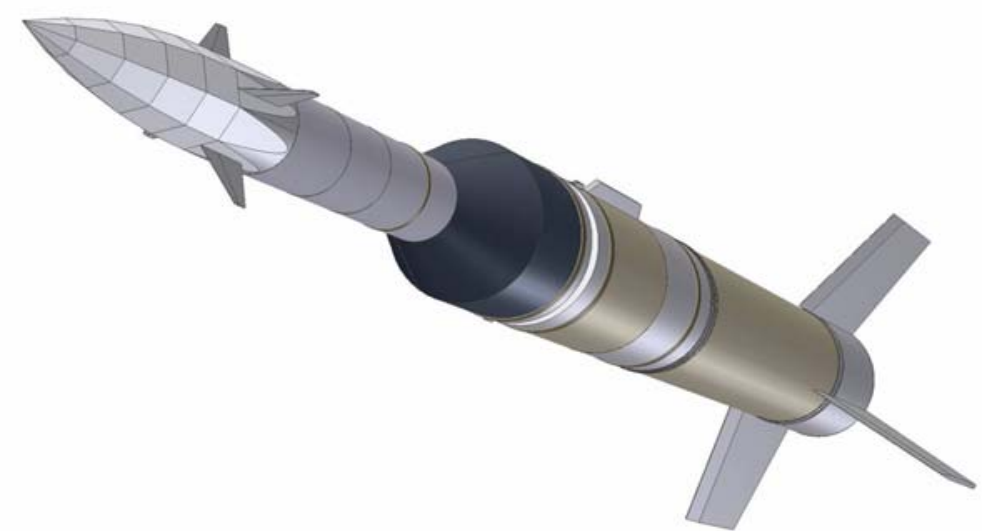

Figure 1: Lay out of the SHEFEX II system including $1^{\text {st }}$ and $2^{\text {nd }}$ stage and re-entry payload

\section{Introduction}

Within the SHEFEX flight test programme, the German Aerospace Center focuses on the development for re-entry and hypersonic technology. Using adapted sounding rocket systems as used for micro gravity research it is possible to perform cost effective flight tests in a short time period. Thus, besides material or structural testing of hardware, the comparison of real flight data with numerical simulations and ground test results is very important to adjust and verify simulation tools and the plausibility of ground test results.

After a successful flight of the first sharp edge flight experiment SHEFEX I at October $27^{\text {th }}$ 2005 the next mission is under preparation. During the $20 \mathrm{sec}$ flight at Ma 6 of SHEFEX I a complete set of valuable aerodynamic data could be obtained. Thus, this kind of flight testing and all experience got up to now will be used to answer new scientific questions and to enlarge the flight envelope by doubling the mach number and re-entry duration within the SHEFEX II mission. [4]

Launched by a Brazilian two staged sounding rocket system SHEFEX II will be a consequent next step in technology test and demonstration. Considering all experience and collected 
flight data obtained during the SHEFEX I Mission, the test vehicle will be enlarged and extended by an active control system, which allows active aerodynamic control during the reentry phase. Thus, besides the facetted ceramic thermal protection system, ceramic based aerodynamic control elements (canards), mechanical actuators and an automatic flight control unit will be implemented as key technology experiments. In addition, supporting subcomponents like different inertial platforms and a star tracker sensor are part of the GNC system of SHEFEX II to provide accurate data related to position and orientation of the vehicle.

In addition, some other experiments including an actively cooled thermal protection element, advanced sensor equipment for temperature, heat flux and pressure, high temperature antenna inserts etc. are intended to fly with SHEFEX II. From national and international companies and universities some passenger experiments will be integrated to investigate and demonstrate advanced metallic and ceramic based thermal protection elements, new fiber optic sensors and a sensor system package, which was developed for ESA's EXPERT mission.

Using a special arrangement of the forward pressure sensors a hypersonic Flush air data system will be integrated at the payload tip as a passive experiment. This is to evaluate such a system and advanced algorithms for active control during hypersonic flight within future missions.

The SHEFEX II launcher system bases on the Brazilian VS40 system. Including the payload the overall length of the system is $12,6 \mathrm{~m}$. The overall mass of the system is 6,7 tons. The $S$ 40 solid rocket motor acts as first stage. Within 60 seconds after ignition a propellant mass of 4 tons lifts the $\mathrm{SH}$ II system up to $54 \mathrm{~km}$ height. Within the first ballistic phase after separation of first stage, the second stage, also a solid rocket motor (S 44) will be re-pointed to a more flat attitude before its ignition. The $800 \mathrm{~kg}$ propellant mass of second stage boosts the SHEFEX II payload to an apogee of approx. $270 \mathrm{~km}$. After a de-spin manoeuvre separation from rocket motor will be initiated and attitude control will orient the payload for reentry at approx. $35^{\circ}$. Re-entry and so the start of experiment phase will be at $100 \mathrm{~km}$ when atmosphere effects became reasonable. The current flight envelope estimates a max. Mach number during entry up to Ma 11 (approx. $3 \mathrm{~km} / \mathrm{sec}$ ) for 45 seconds. This high Mach number will cause extreme heat fluxes at the payload tip and sharp leading edges at the canards and stabilizers. So temperatures above $1800^{\circ} \mathrm{C}$ may occur at these exposed locations. The dynamic pressure will increase up to 4 bar at the end of entry trajectory at $20 \mathrm{~km}$.

\section{Predicted Reentry Parameter}

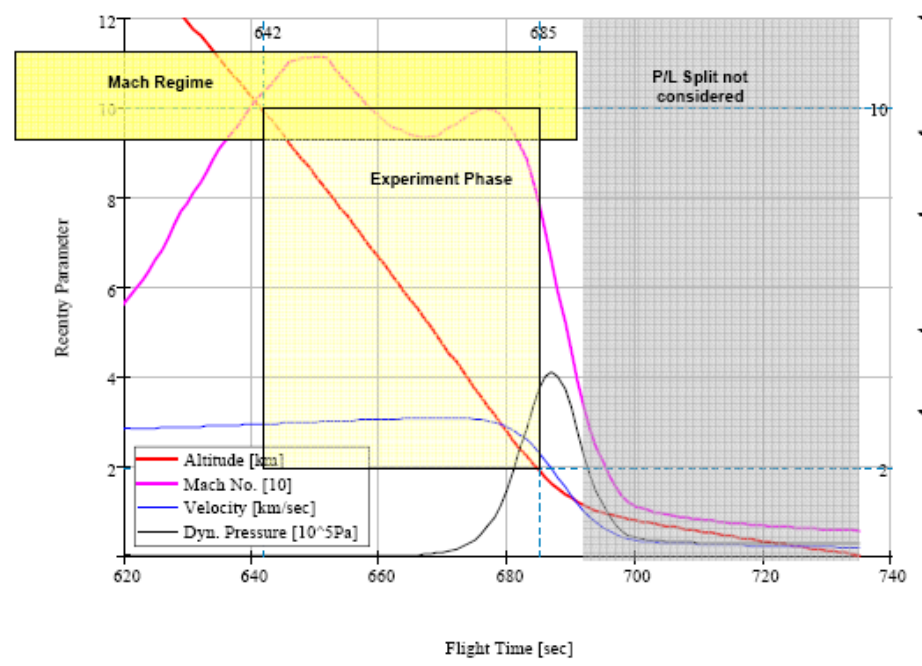

7 Mach no. regime $\mathrm{M} \approx$ 11.1 to $9.3(v \approx 3.0-$ $2.9 \mathrm{~km} / \mathrm{sec}$ )

7 Experiment time from 100 to $20 \mathrm{~km} \mathrm{t}_{\exp } \approx 45 \mathrm{sec}$

$>$ Max. dynamic pressure up to $400 \mathrm{kPa}$ during experiment phase

$>\mathrm{P} / \mathrm{L}$ split at $\mathrm{h} \approx 15 \mathrm{~km}(\mathrm{M} \approx$ 5.9)

$>$ Begin of both recovery sequences at $h \approx 4 \mathrm{~km}$

Figure 2: Predicted re-entry parameter 
Below $20 \mathrm{~km}$ the payload will be split and decelerated by an unstable tumbling of both separated parts. At $4 \mathrm{~km}$ a parachute system will be deployed to reduce landing velocity to finally $9 \mathrm{~m} / \mathrm{s}$. Launched at Andoya Rocket Range in Norway, the target area for land landing has been chosen at the east of Svalbard, approx. $1100 \mathrm{~km}$ north from the launch site. Recovery operation will be initiated form Longyearbyen via Helicopter.

Due to the complex modifications at the rocket system itself a first configuration test using a simplified pay load structure is intended to be performed in advance. This is to demonstrate stability of the system during the first seconds of ascent, to verify save stage separation, repointing of second stage and finally to test the recovery systems. Considering this test flight which is scheduled in spring 2010 the final launch date is planned for spring 2011. The launch window is limited by weather and day light condition at the target area.

\section{Launch vehicle lay out}

$$
\text { Rocket Motor System (RMS) }
$$

After a trade off of different launcher configurations and examination of each possible performance and related trajectory, a final 2 stage configuration was chosen considering Brazilian solid rocket boosters derived from the $\mathbf{S} 40$ family.

The RMS was originally designed and developed by CTA Brazil to collect vacuum in-flight data of the S44 motor, designated as the fourth stage of CTA's satellite launcher VLS. The S44 motor case and the interstage adapters are lightweight structures built of Kevlar composites. The burning time is $60 \mathrm{sec}$.

The VS-40 was first launched in April 1993 achieving an apogee of $950 \mathrm{~km}$ and a ground range of 2,680 km with a payload mass of $197 \mathrm{~kg}$ at 81.8 degree launch elevation. Up to now, two flights are recorded, both successful. [5]

With focus on the experiment phase for the SHEFEX 2 experimental vehicle the conventional parabolic trajectory for unguided sounding rockets was modified with respect to lower apogee but longer re-entry and atmospheric flight sequence. This modification requires an exo-atmospheric repointing manoeuvre under spinning conditions after first stage burn-out and separation, by the ACS cold gas thruster system. The remaining vehicle will be pointed and the roll axis aligned with a low elevation angle (e.g. 0 deg to $10 \mathrm{deg}$ ) before ignition of

\section{Preliminary Altitude vs. Ground Range}

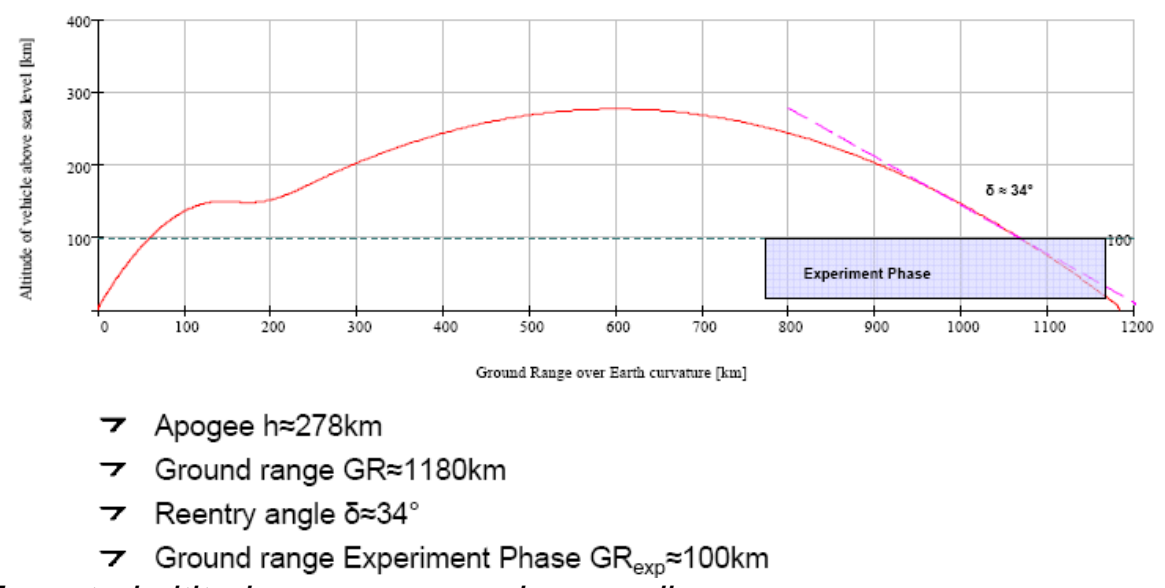

Figure 3: Expected altitude versus ground range diagram 
the S44 motor. After S44 burn-out the spin will be removed by a yo-yo de-spin system. The ACS will set the re-entry attitude of the experimental vehicle. Due to the limited thrust of the cold gas system and high inertia of the vehicle the re-pointing is assumed to take approximately $100 \mathrm{sec}$.

The following figures and tables display the preliminary flight performance. The maximum altitude for this scenario is approximately $215 \mathrm{~km}$, the ground range is predicted as $1,170 \mathrm{~km}$. The re-entry flight path angle at $100 \mathrm{~km}$ is approximately 30 degrees.

The experimental phase on the downleg from $100 \mathrm{~km}$ down to $20 \mathrm{~km}$ comprises 50 seconds of experimental time providing velocities in the region of $3.1 \mathrm{~km} / \mathrm{sec}$ and $2.7 \mathrm{~km} / \mathrm{sec}$ respectively which conforms to a Mach regime between 11.0 and 9.5.

\section{Mechanical Flight Systems}

The implementation of a new vehicle with an unusual payload form, guidance system and trajectory performance criteria as well as a recovery operation requiring extreme aerodynamic braking at a low altitude has imposed a wealth of technical problems in the mechanical design. The main problem areas are the aerodynamic stability of the complete vehicle during ascent in spite of payload fins and inactive canards, active separation of the two motors after an extended coast phase, incorporation of two cold gas systems with thrusters at optimum locations and splitting the payload at hypersonic velocities for prerecovery aerodynamic braking. In addition, a payload length of 5.5 metres and a maximum mass of $350 \mathrm{~kg}$ was the target.

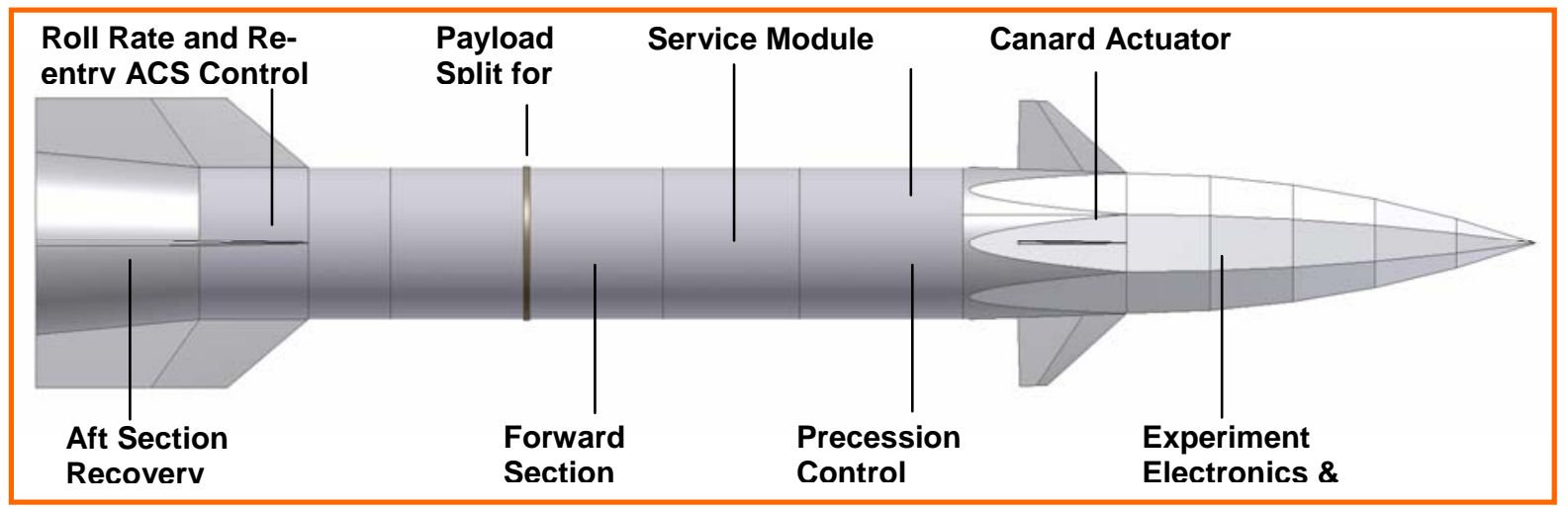

Figure 4: Main components of the re-entry payload

\section{Fairings and Motor Fins}

A solution for the payload fin and canard problem would have been to place a fairing over the complete payload, however, the increased mass would have reduced the performance of the first stage and particularly the second stage unless it could be ejected under spin before ignition. The qualification of such a system were considered to exceed our resources. A compromise was chosen which comprises a small fairing over the payload fins which will be ejected after S44 burnout and despin. The fairing will be of composite material and consist of two or four segments approximately 1.4 metres in length which are released by pyrotechnic actuators on the payload and the attachment module. The canards will be locked by retractable pins until apogee but as they are exposed, still contribute to the need for larger but lightweight fins on the S40. The S40 fins with a span of greater than 1 metre and an extended root chord on the motor case provide the required liftoff stability. The design and construction of these fins will be performed in a cooperation with the DLR Stuttgart institute for materials research. 
The interface between the S44 motor and the payload fulfills several functions. A YO-YO despin system removes the $2 \mathrm{~Hz}$ spin rate which is required to stabilize the burn phase of the S44. The forward end of the attachment module is used to clamp the aft end of the payload fin fairings. Once the fairings are released, a manacle ring clamping the aft end of the smaller diameter $(600 \mathrm{~mm})$ payload flare adapter to the attachment module is released and simultaneously 3 separation plungers accelerate the payload away from the motor.

\section{Payload Fins}

The payload fins are small span fixed stabilizers of about $1200 \mathrm{~mm}$ root chord length and $230 \mathrm{~mm}$ span and are constructed from high temperature resistant composite material because of the aerodynamic and thermal loading during re-entry. Because of the necessity for roll rate control with a large inertia filled S44 motor, the roll thrusters must be integrated into the fins for maximum torque moment arm. In addition, as these fins will be on the prime payload axes, the lateral control thrusters must also be integrated into the aft end of the fins. This in turn means that the fairings must include a cut out at least for the roll thrusters which will be operated before fairing ejection.

\section{Recovery}

At approximately $15 \mathrm{~km}$ altitude on the descent, the payload will be separated by a manacle ring release and high velocity separation system into two sections which are inherently unstable. This will produce a tumbling motion with extremely high deceleration which results in velocities of less that 250 metres per second by the time the payload sections have descended to $4.5 \mathrm{~km}$, where the heat shields are deployed and normal recovery parachute system operation is possible. Experience with the SHEFEX 1 payload has shown that provided the problem of ram air spikes is accounted for and the centres of gravity of the payload sections are correctly placed, that the aerodynamic braking is adequate. High velocity recovery systems are installed at the aft ends of both payload sections.

\section{On Board Data Communication and Telemetry}

The Service System comprises a redundant S-Band transmitting system consisting of two 10W RF transmitters and two antennae systems. This enables the ground stations to receive the downlink using both polarization and frequency diversity at the same time. One antennae system uses four MORABA high temperature antennae which have been flight qualified during the SHEFEX I mission. The second antennae system consists of two patch antennae residing under RF transparent Whipox thermal protection tiles. In addition, all PCM data is recorded with an onboard solid state recorder and can be retrieved after recovery of the payload.

The payload telecommand system is identical to the system used for the SHEFEX 1 project. The onboard system comprises two L-Band telecommand receivers coupled to two high temperature antenna spaced at $180^{\circ}$.

During the ascent of the vehicle, real time video data from a camera looking aft will be transmitted to the ground station using a S-Band $10 \mathrm{~W}$ video transmitter. The RF output of this transmitter is connected to the same combining network and antennae array which is used for transmitting the payload TX1 PCM data but in this case a left hand circular polarized field (LHCP) is radiated to further decouple the transmitters. After deployment of the S44 and payload fairings, a second camera looking forward from the payload flare will use this link. At separation of the two payload sections and shortly before activation of the recovery system, the video input to the transmitter is switched to a third camera in order to monitor the recovery sequence. 
The transmission standard for the colour video signal is PAL-G using the CCIR 405 convention. As with the payload PCM data, all video information is recorded with a solid state recorder on board the payload.

The payload is equipped with a 400W radar transponder and an appropriate antennae system which receives and transmits with a circular polarization. In addition, the qualified DLR ORION GPS receiver will be used to obtain velocity and position data. The onboard generated IIP information is used as a backup source to the ground safety system using radar data.

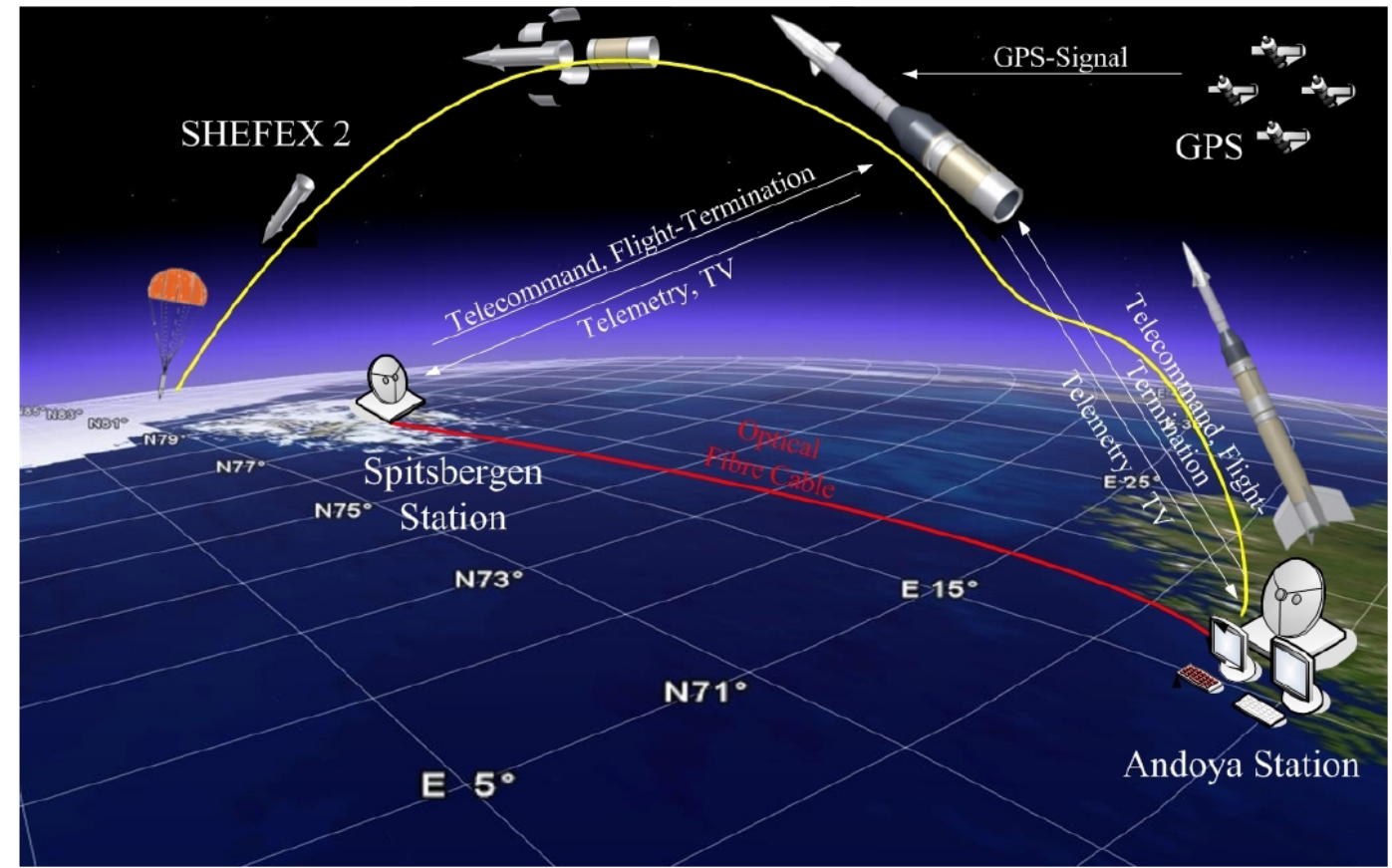

Figure 5: Mission overview and telemetry communications

\section{Launch mission and campaign}

At Andenes Rocket Range the $3 \mathrm{~m}$ and the $6 \mathrm{~m}$ monopuls tracking stations will we used to receive the payload PCM data and the video images. Both receiving chains are configured to provide polarization and frequency diversity reception. This concept will ensure good data quality during that part of the trajectory visible from the range. The ARR mobile telemetry station will be located and operated in the same way as during the SHEFEX I mission. During this flight, the station demonstrated its value at this local elevated position. With this station it will be possible to receive direct payload data down to a flight altitude of less than $100 \mathrm{~km}$ on the down-leg part of the trajectory.

The MORABA mobile telemetry station will be set up on the elevated plateau at Longyearbyen. This position enables the reception of the payload signals as soon as the vehicle is visible over the local horizon which corresponds to a flight altitude of approximately $70 \mathrm{~km}$ on the ascent. From this point onwards the payload data is received and the demodulated PCM signal is sent back to Andenes using the submarine high data rate optical fibre link. As the ground range to the nominal landing point of the payload is in the order of $300 \mathrm{~km}$, the RF link can be maintained down to an altitude of $\sim 4 \mathrm{~km}$. As the initiation of the recovery sequence will start in about $15 \mathrm{~km}$ altitude with splitting the payload, most of the recovery events can be monitored. A second payload telecommand station will be used at this location to transmit commands which are received through the optical fibre connection from the payload engineer at Andøya as soon as a reliable downlink to the payload is achieved. 
A preliminary link budget calculation for the main tracking stations at Andenes during the whole time of visibility shows a comfortable $6 \mathrm{~dB}$ margin (not including the pre-detection diversity improvement) when using $10 \mathrm{~W}$ payload transmitters for the PCM data.

For the TV link a minimum video signal quality of $\sim 30 \mathrm{~dB}$ can be expected. At all times an adequate link margin is guaranteed with the high power destruct and payload command transmitters.

\section{Safety}

As the second stage of the VS-40 vehicle will be re-oriented with an active control system before ignition, a fully redundant flight termination system is necessary. This system permits the destruction of the S44 motor in the case of an abnormal flight.

During the burn phase of the first stage, the system is treated as a normal unguided sounding rocket. The ignition of the second stage is effectively controlled by a number of conditions like

- Precession maneuver achieved

- Ignition time window open

- TC ignition inhibit not active

The onboard inertial guidance platform signals to the ignition system that the pointing of the second stage is achieved and correct. Via telemetry, the payload engineer and safety officer can verify this information on ground and correlate with additional information such as payload GPS and radar. Should there be a failure of the attitude control system, an ignition inhibit signal can be sent to the second stage ignition system by the payload telecommand system. Should all conditions be fulfilled, the second stage will ignite at a preset time.

\section{Aerodynamic issues}

A major problem in hypersonic aerodynamics is with respect the limited capabilities of ground-based test facilities to simulate hypersonic flow. The technology to design and develop a wind tunnel that can fully reproduce hypersonic flow as encountered during atmospheric re-entry, is not available now or in the near future. Furthermore, the hypersonic aerothermodynamic database gained in flight tests is rather limited and not always available in the open literature. Thus the aerodynamic design of a hypersonic vehicle heavily depends on Computational Fluid Dynamics (CFD) with computer codes that are not sufficiently validated by ground based facilities. As a result the designer of hypersonic vehicles must apply a methodology based on a clever combination of CFD, wind-tunnel tests and flight tests. Beside such design difficulties, flight tests can be used for the qualification of thermal protection systems (TPS) and TPS-materials and for obtaining experience in other system level technologies. Indeed, the enormous amount of scientific data obtained with the SHEFEX I flight experiment [1] emphasized that relatively straightforward experiments are an essential source to acquire knowledge in the physics of hypersonic flight and in the development of more complex vehicles.
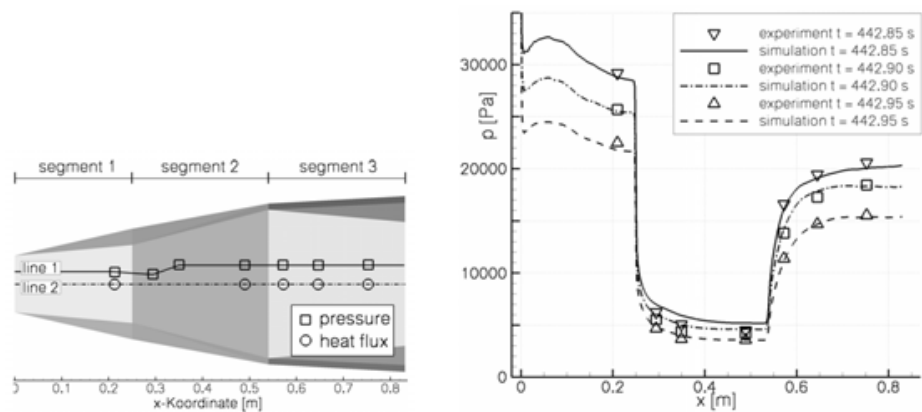

Figure 6: Position of the pressure sensors and comparison of experimental data with CFD predictions [1] 
The application of the knowledge acquired with SHEFEX I encouraged DLR to implement a step by step approach towards a fully controlled re-entry vehicle. It is interesting in future vehicles to use aerodynamic control to gather the re-entry. A disadvantage of a ballistic reentry is the limited maneuverability, so that it becomes difficult to cope with flight-path constrains like the heat flux or total load. These difficulties can only be overcome by actively controlling the aerodynamic forces acting during re-entry. Thus a flight experiment devoted to test new re-entry guidance and control algorithm is of importance for future vehicle developments. Additionally, from a fluid mechanics point of view a flight experiment devoted to an actively aerodynamic controlled vehicle provides a platform to accumulate know-how on flap efficiency and flap heating due to shock-wave boundary layer interaction and shockshock interaction. Therefore, the goal of the SHEFEX II experiment is to demonstrate for the first time in Europe a hypersonic re-entry with a fully aerodynamic controlled vehicle. Using a facetted axial symmetric vehicle configuration, a re-entry trajectory is being designed for Mach numbers between $9<\mathrm{M}<11$ in the altitude range 100 to $20 \mathrm{~km}$.

Beside the above mentioned system challenges, at the Institute of Aerodynamics and Flow Technology other goals are envisage towards in the future, a virtual design of space vehicles. Due to the significant technical progress in computer technology and computational fluid mechanics increasingly strategies for the direct interdisciplinary coupling between fluid mechanics and structure mechanics or aerodynamics and flight mechanics are developed. Within the design process of hypersonic aircraft a direct coupling between fluid mechanics and flight mechanics enables an immediate analysis of a projected vehicle. For hypersonic vehicles this is of special interest, because their layout currently requires complex aerodynamic datasets which depend on Mach number, Angles of Attack and Yaw as well as on control surface deflections. Additionally, usually the complete trajectory from hypersonic cruise flight / re-entry until subsonic landing has to be covered. Currently, the direct coupling of CFD and flight mechanics is still much too time-consuming to consider the free motion of a vehicle along a complete trajectory. Therefore, in a first attempt it is the goal to use the flight of SHEFEX II to assess the tool resulted from the modular coupling procedure between the DLR surface inclination method SOSE and the trajectory optimization code REENT of the University of Stuttgart [2]. The modular layout of such coupling procedure allows the consideration of complete arbitrarily staged missions without and with propulsion, where the propulsion systems may be considered applying a bookkeeping procedure and within 6DOF simulations e.g. also the time dependent change of the inertial tensor due to fuel consumption is taken into account.
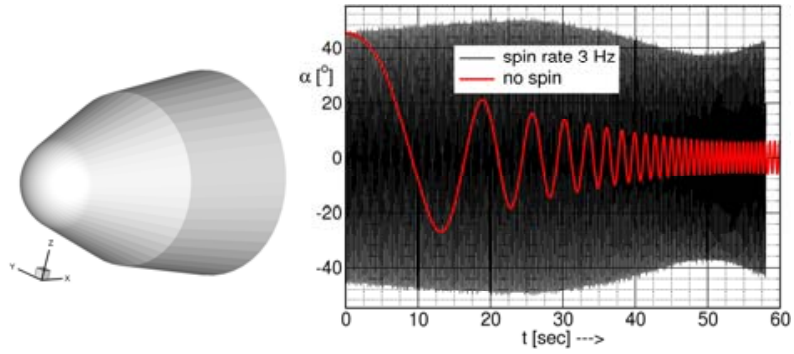

Figure 7: Influence of the spin rate on the motion of a bi-conic capsule in hypersonic flow [2]

While currently the code is well suited for the definition of staged sounding rocket experiments, in future applications more sophisticated fluid mechanic methods like the DLR Euler- and Navier-Stokes code TAU, may be easily introduced. Such new multi-disciplinary approach, involving computational fluid dynamics and flight mechanics will allow full dynamic analysis of controlled free flying vehicles. Within the DLR project IMPULSE a 6-DOF motion model has been recently implemented in TAU. This tool couples numeric aerodynamic simulations with rigid body motions directly. As an essential prerequisite, simulation of 
maneuvers requires a consideration of vehicles control surfaces. This control surface integration provides a challenge for numerical investigations due to the treatment of the mesh, which must move with the control surface. In order to avoid a new mesh generation for each surface deflection, the technique of overlaid grids, Chimera-Technique, is utilized to integrate the control surfaces. This new multi-disciplinary approach, to be validated through the SHEFEX II flight experiment, will help the design of future hypersonic vehicles and control systems. In particular, the method envisaged offers more precise dynamic analysis allowing also accurate prediction of the dynamic behavior of hypersonic vehicles, a feature of strong importance for non-winged configurations like lifting bodies and capsules.

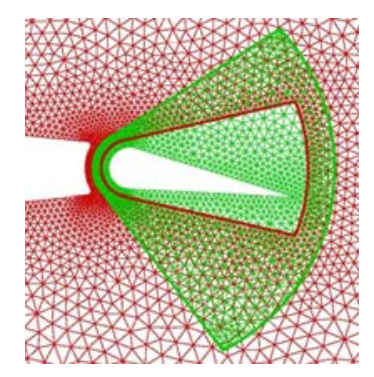

\section{Architecture of the payload Tip}

The primary substructure of the payload tip is similar to the SHEFEX I concept and consists of a aluminium frame created by stiff booms and spares. The free space is closed by flat aluminium panels, which create an inner mould line (IML). The panels are also used for mounting the TPS facets and experiments. Inside the frame, some measurement equipment is integrated. These items are boxes for thermocouple connection and compensation, pressure transducers, a pyrometer system, data processing boxes and subsystems for passenger experiments.

The tip geometry is symmetrically divided into 8 identical facets in circular direction and consists of 5 segments along the tip to the actuator module interface. Thus, the payload tip houses 40 single flat areas. 32 of them are available for different experiment positions.

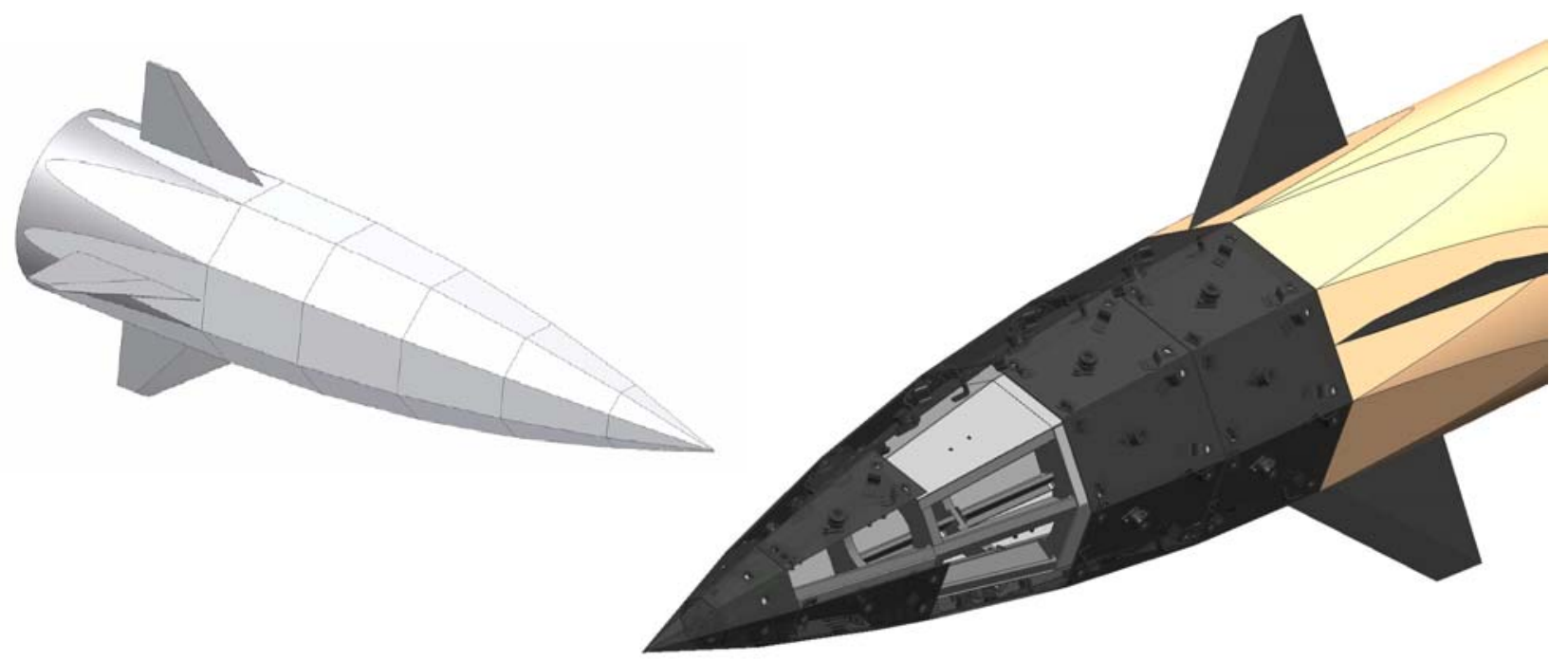

Figure 8: Outer mould line (OML) of Payload tip and actuator module (left). TPS (dark grey) and inner aluminium substructure (light grey) (right) 


\section{Thermal Protection System}

The basic TPS system is based on the segmented concept developed within an ESA Program. Main element of the concept is a fiberceramic cover plate, supported in all directions by a so called central post and flexible stand offs at the corners. Thus, the thermal expansion will be not suppressed. Beneath the cover plate a lightweight fibrous ceramic insulation felt is inserted.

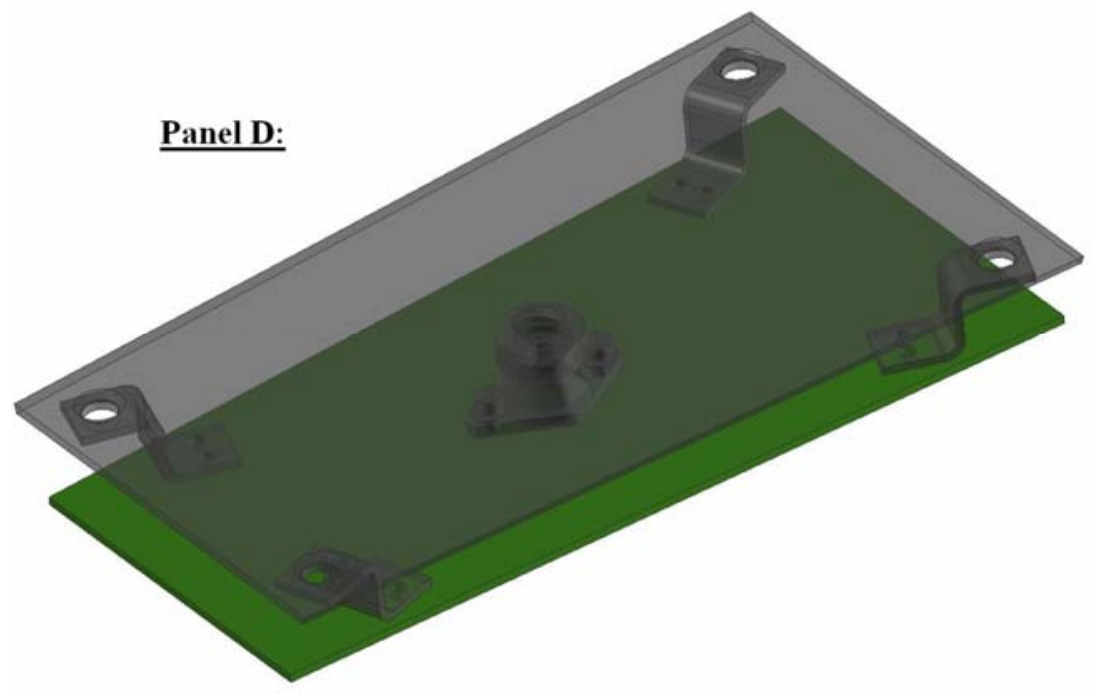

Figure 9: Principal lay out of standard TPS segment consisting of CMC Panel, Stand-off and central post (grey) and aluminium sub-panel (green). Insulation removed.

\section{CMC Screw rivet fastener}

Key element of this TPS concept is a ceramic fastener, used for the connection of the panel to the CMC stand off and central post. A novel CMC fastener consisting of a bolt with a conical or spherically shaped head and a split threaded shank has been developed at DLR.

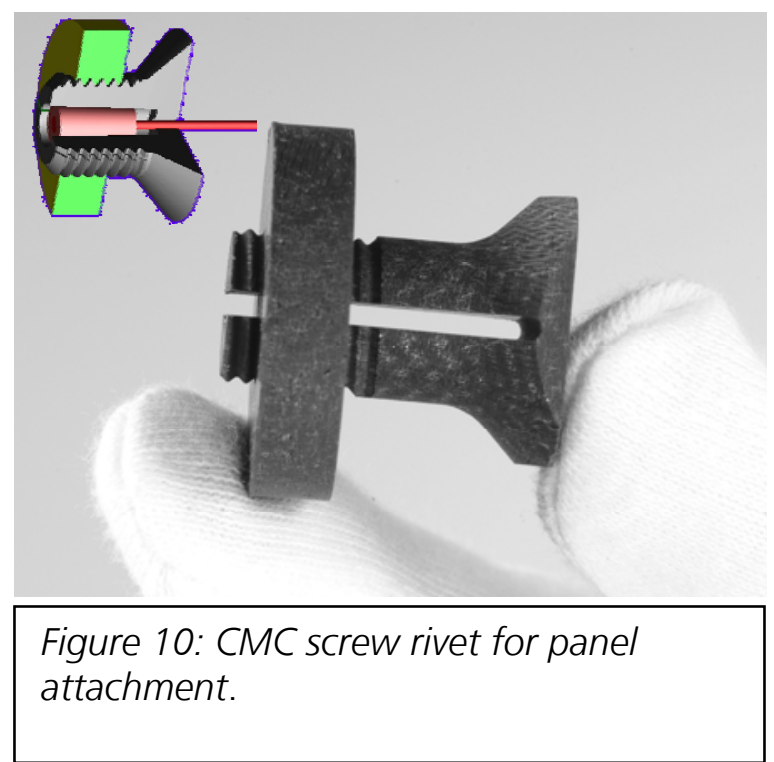

At first, the fastener is screwed in with no deformation. When the torque moment reaches a particular level, the shank of the fastener, which is in the nut, is pressed together until the inner cone or the slot limits further deformation. By drawing the inner cone with a pin axially, 
the shank of the fastener is spread back resulting in a pretension in both radial and axial directions as both flanges of thread and nut are pressed together. Thus the torque moment during fastening is low. This is another positive effect, because the torsion strength of CMC materials is usually low due to the low interlaminar shear strength of the material. Thus, the screw rivet design provides and combines nearly the same functionality as a common screw and a blind rivet, but the internal stress distribution is more adequate due to CMC material properties. To loosen this element it is only necessary to press down the conical locking element.

Within the SHEFEX I project, the detailed shape of the fastener has been improved and mechanical strength could be significantly enhanced. Within SHEFEX II further optimisation could be achieved in terms of reliability and mounting rules. Thus, the demonstration of functionality and reliability for operational application of such screw rivet attachments is on track.

Within the flight unit all facets of the 4 segments behind the nose are created by single CMC panels. However, the facets of the first nose segment are too small for single panels, thus, this part was designed and manufactured as one integral nose cone, but also connected using flexible stand offs and screw rivets. One key experiment located inside the nose is the flush air data system, which is realized by 8 symmetric pressure sensor holes.

In total, a number of 180 screw rivets are necessary for the assembly of the flight unit. Enough to get experience in practical use considering cost effective manufacturing, fixation, quality assurance and loosening procedures after flight.

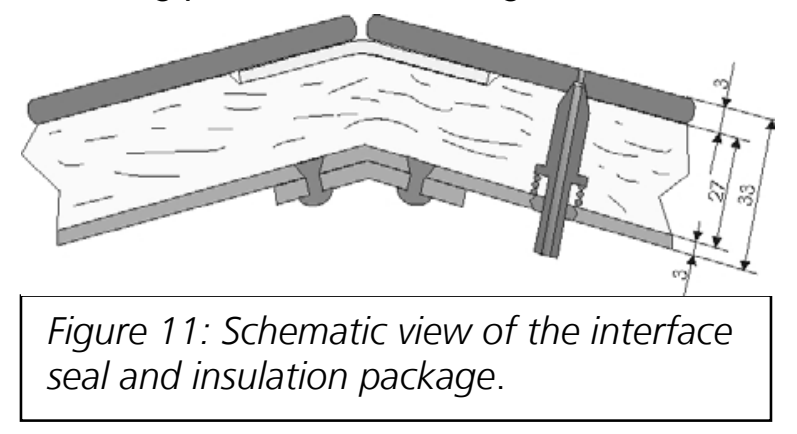

\section{Interface seal design}

The second key element for the TPS is the seal design at the interfaces between the panels. During the nose cap development for X-38 a rigid and flexible seal combination was developed. During a lot of ground tests within plasma wind tunnel test facilities, the performance and reliability could be demonstrated. However, the manufacturing effort was rather high to adopt the rigid seal contour close to the panel shape. Within the SHEFEX shape including a certain number of different angles at the interface chamfers, a lot of different single parts would be necessary.

A new approach will be performed within the SHEFEX project. Within DLR an oxide ceramic based CMC material was developed during the last years. The so called WHIPOX material can be used as an oxidation stable alternative to carbon based CMCs. However, temperature stability is limited and a special coating is necessary to improve emissivity and catalytic behaviour. Nevertheless, this material provides a flexible intermediate state during the manufacturing process. Thus, it is possible to shape a component (in case of SHEFEX the rigid seal) during assembly. Hardening will occur during operation.

Using this property, it is possible to shape and cut all required seal components from one uniform WHIPOX tape. A typical seal interface was tested within a plasma wind tunnel and 
handling procedure, seal performance and temperature stability could be demonstrated successfully.

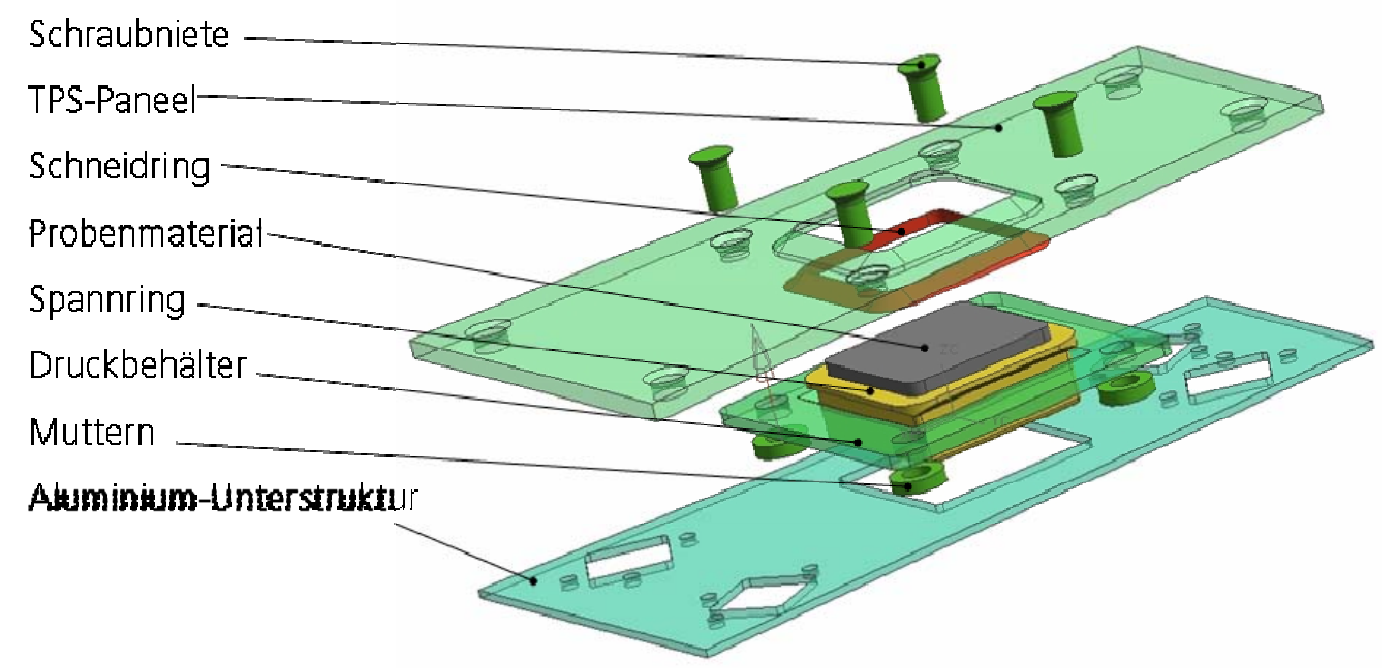

Figure 12: Exploded view of the AKTIV experiment. CMC panel and screw rivets (green), porous sample (grey), pressure tank (yellow).

\section{One key experiment AKTIV: Actively cooled TPS}

In parallel, an actively cooled concept is under investigation. Based on the very good experience got during development of an effusion cooled ceramic rocket engine burning chamber, it seems to be possible to transfer this technology for the design of extremely loaded sharp leading edges or flat TPS elements exposed to heat fluxes beyond materials temperature limits. First screening tests of different porous ceramic materials and cooling gases showed a promising potential for this technique. Significant cooling effects at rather low gas consumption could be demonstrated within a plasma channel test sequence at hypersonic gas flow conditions. However, a large effort has to be invested to investigate and understand the responsible parameters for an optimal cooling effect considering the thermal conductivity and interactions between the surrounding gas flow and boundary layer.

Active cooling systems are of special interest for use in severe thermal environments where the passive systems are inadequate. The transpiration cooling experiment uses a porous ceramic material at the outer surface through which a coolant flows into the boundary layer. Thus, transpiration cooling is effected by two physical phenomena, as there are the porous structure being convection cooled by the coolant and the coolant layer on the outer, hot surface, lowering the heat transfer from the high-enthalpy environment to the vehicle surface.

In the centre of a pair of the flat thermal protection system (TPS) panels, a porous probe will be inserted. This porous probe is to be run through by the coolant and is pressed into the surrounding $\mathrm{C} / \mathrm{C}$-SiC TPS-material by a compression ring. The pressure reservoir is flanged to the $\mathrm{C} / \mathrm{C}$-SiC ceramic by riveted ceramic fasteners. The reservoir itself is made of stainless steel.

To this point, a numeric FE-analysis of the experiment set-up was performed. Investigations of a similar set-up were successfully completed in a plasma wind-tunnel and provide a basis for the present experiment. In addition, the impact to the whole gas flow characteristic at the payload tip caused by the boundary layer interaction with the cooling gas will be simulated by CFD and wind tunnel investigations. 


\section{Instrumentation}

One big issue of the SHEFEX II mission is to collect flight data. Thus approx. 60

Thermocouples outside, 20 temperature sensors inside, 25 pressure sensors and 8 heat flux sensors will be integrated at the payload tip. Special care will be applied to the integration of the pressure and heat flux sensors within the TPS elements. This is to minimize secondary gas flow effects at the sensor/ceramic interface at the outer surface. Otherwise, the heat flux signal may be disturbed by local turbulence or stagnation areas. All signals will be processed and send to the data storage and telemetry system by special multi function cards also integrated within the payload tip. Lessons learnt from SHEFEX I and parallel on ground testing and calibration promises a high quality of flight data, which will allow optimisation and calibration of CFD tools for further reliable aerothermodynamic vehicle lay out.
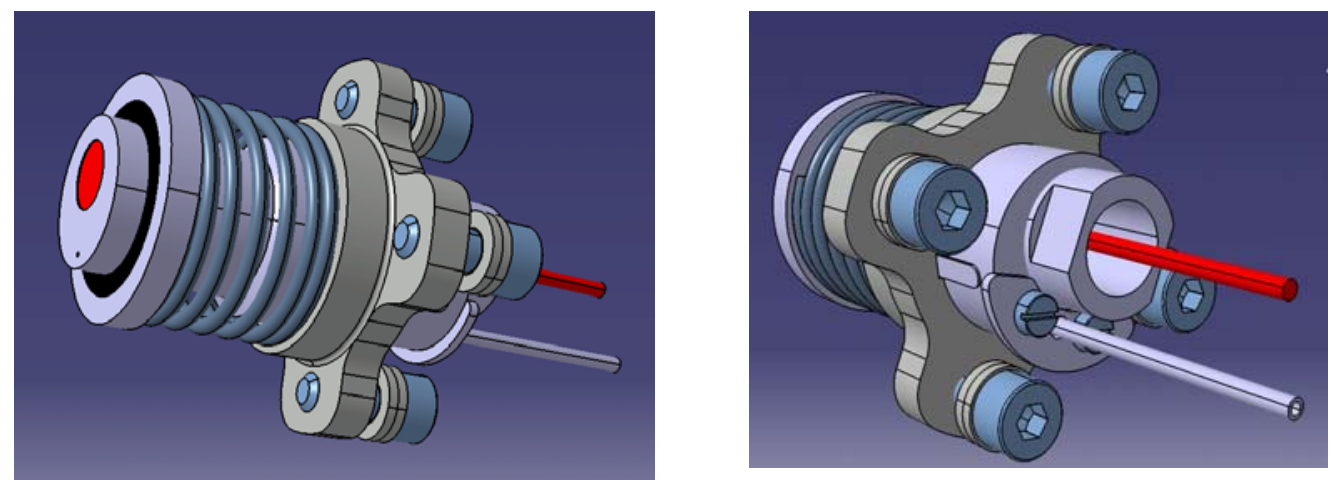

Figure 13: Lay out of a combined heat flux and pressure sensor to be accommodated within a TPS segment.

\section{Conclusion}

Shefex II is one more step forward within DLR's roadmap for the development of hypersonic and re-entry technology. A first application is planned within the Returnable Experiment REX. Such a system shall provide a free flying platform with a high micro g quality for a few days. The return capability, active aerodynamic control during re-entry and the special container technique derived from sounding rocket experiment set up shall provide a cost effective and easy access for experimenters. Thus, the currently prepared SHEFEX II mission is not a single project or "only" a re-flight of the first experiment. This project is part of a long term flight test program for re-entry technology and related development items.

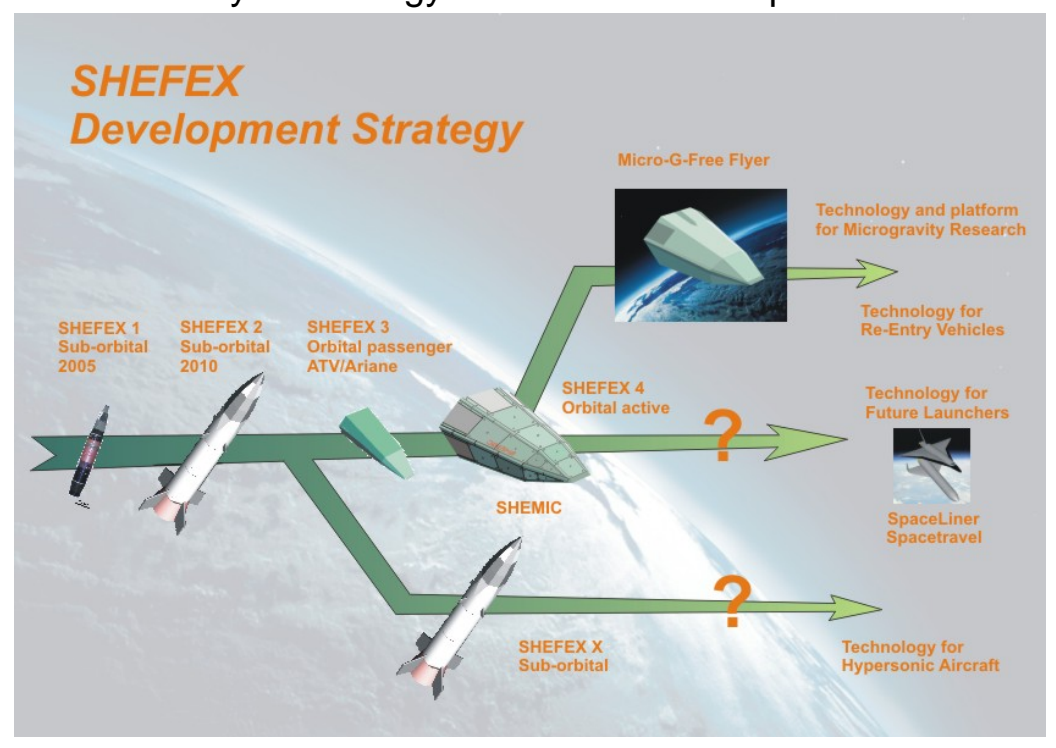

Figure 14: Development roadmap of SHEFEX test flight program. 
The following DLR Institutes and Facilities participate within the SHEFEX II Project:

Institute of Aerodynamics and Flow Technology, Braunschweig / Göttingen and Wind Tunnels Section, Cologne, Institute of Structures and Design, Stuttgart, Institute of Flight Systems, Braunschweig; Institute of Materials Research, Cologne, Institute of Aerospace Systems, Bremen, Mobile Rocket Base MORABA, Space Operation and Astronaut Training, Oberpfaffenhofen

\section{Literature:}

[1]

[2]

[3]

[4]

[5]

[6]

[7]

[8]

[9]

[10]

[11]

[12]

Barth, T., Aero- and Thermodynamic Analysis of SHEFEX I, Engineering Applications of Computational Fluid Mechanics Vol. 2, No.1, pp. 76-84, 2008

Eggers, Th., Gräßlin, M., Layout of Hypersonic Vehicles by Coupling of Aerodynamics and Flight mechanics, 2nd International ARA Days, Arcachon, October 2008.

Korfanty, M., CFD based Dynamic Analysis of Atmospheric Re-Entry Vehicles, 2nd International ARA Days, Arcachon, October 2008.

Weihs, H., Longo, J., Gülhan, A.: The sharp edge flight experiment SHEFEX. 4th European Workshop on Hot Structures and TPS for Space Vehicles, Palermo, Italien, 26-29 November 2002, ESA/ASI/DLR/CNES, (2002)

Boscov J. and Macera S.R., Programme Spatial Brésilien: La Fusée VS-40, Proceedings of the $11^{\text {th }}$ ESA Symposium on European Rocket and Balloon Programmes and Related Research, Montreux, Switzerland, 24 - 28 May, (ESA SP355, March 1994).

Eggers Th., "Aerodynamic and Aerothermodynamic Layout of the Hypersonic Flight Experiment SHEFEX" $5^{\text {th }}$ European Symposium on Aerothermodynamics for Space Vehicles, ESA Nov. 2004.

Eggers Th., Longo J., Hörschgen M., Stamminger A., "The Hypersonic Flight Experiment SHEFEX" AIAA $13^{\text {th }}$ Space Planes and Hypersonic Systems and Technologies Conference, AIAA May 2005.

Eggers Th., Stamminger A., Hörschgen M., Jung, W., Turner J., "The Hypersonic Experiment SHEFEX - Aerothermodynamic Layout, Vehicle Development and First Flight Results" ESA $6^{\text {th }}$ International Symposium on Launcher Technologies, ESA Nov. 2005.

Longo J., Püttmann, N., "The DLR Sharp Edge Flight Experiment SHEFEX" Proceedings of the DGLR Jahrestagung, DGLR 2004-072, September 2004.

Stamminger A., Turner J., Hörschgen M., Jung W., "Sounding Rockets as a Real Flight Platform for Aerothermodynamic CFD Validation of Hypersonic Flight Experiments", $5^{\text {th }}$ European Symposium on Aerothermodynamics for Space Vehicles, ESA Nov. 2004.

Turner J., Hörschgen M., Turner, P., Ettl, J., Jung W., Stamminger A., "SHEFEX - The Vehicle and Sub-Systems for a Hypersonic Re-Entry Flight Experiment", $17^{\text {th }}$ ESA Symposium on European Rockets and Balloon Programmes and Related Research, ESA 2005.

Weihs H., Turner J., Hörschgen M.., "SHEFEX II - The Next Step within Flight Testing of Re-Entry Technology", 57th International Astronautical Congress, Valencia, Oct. 2006. 